\title{
Moisture conditions in coated wood panels during 18 months natural weathering at five sites in Europe
}

Gerhard Grüll ${ }^{1}$, Michael Truskaller ${ }^{1}$, Laurence Podgorski ${ }^{2}$, Susanne Bollmus ${ }^{3}$, Imke De Windt ${ }^{4}$, Ed Suttie ${ }^{5}$

${ }^{1}$ Holzforschung Austria, Franz Grill Strasse 7, A-1030 Wien, Austria

${ }^{2}$ FCBA, Allée de Boutaut BP227, F-33028 Bordeaux Cedex, France

${ }^{3}$ Georg-August-University of Göttingen, Wood Biology and Wood Products, Büsgenweg 4, D-37077 Göttingen, Germany

${ }^{4}$ Ghent University, Faculty of Bioscience Engineering, Laboratory of Wood Technology, Coupure Links 653, B-9000 Gent, Belgium

${ }^{5}$ Building Research Establishment, Garston, Watford WD2 7JR, United Kingdom

ABSTRACT: Wood moisture content of coated panels of Scots pine sapwood was recorded during 18 months natural weathering in Vienna by logging electric resistance and temperature near the surface. Eight coating systems with various film thicknesses were used, including three solvent borne alkyd stains, three water borne acrylic stains and two water borne acrylic paints. At five sites in Europe wood moisture content of panels coated with three solvent borne alkyd stains, a brow acrylic stain and a white opaque acrylic paint was recorded weekly by changes in panel mass. Fluctuations in wood moisture content were influenced by the film thickness, moisture protection and colour of the coating systems used. Degradation phenomena led to decreasing moisture protection of less durable coating systems over time of exposure. Differences between the exposure sites were relatively low, except the site in the UK where moisture conditions were higher.

\section{Introduction}

A good moisture balance in wood is the key to durability of all timber constructions. Maintaining low levels of wood moisture content below critical limits and short times of wetness by fast moisture release is of great importance to reduce the risk of decay by wood destroying fungi (Rapp et al. 2000, Brischke 2007, Viitanen et al. 2010). In exterior use the response of wood moisture content to weathering conditions is of interest, where rainfall, humidity and temperature are decisive parameters. Different conditions are present at different exposure sites and exposure situations of individual constructions.

Coating systems are able to protect wood against moisture ingress and they influence moisture release depending on their permeability for liquid water and water vapour (Wassipaul and Janotta 1972, Janotta 1973, Hora and Böttcher 1995, De Meijer and Militz 2001, Ekstedt 2002, Svane 2004). Moisture conditions in coated panels exposed $45^{\circ}$ facing south were investigated by Derbyshire and Miller (1996) by recording wood moisture content with conductivity measurements on a site in the UK. In an initial period of time they found small fluctuations and small differences between coating systems but the length of the period of moisture stability ranged wide depending on the coating system. De Windt et al. (2009) employed load cells with a data logging system to carry out continuous moisture measurements in coated specimens of different wood species aiming at service life estimation. They found an effect of coating type and wood substrate on moisture conditions in coated wood. The effect of the coating type decreased while the effect of the substrate increased with proceeding erosion of the coating system. Fitl et al. (2007) reported on the influence of liquid water permeability and paint colour on moisture fluctuations in a ventilated cladding facing southwest. Short term moisture fluctuations 
were smaller when a less permeable paint was used and with an opaque white coating system the panels remained at higher wood moisture contents during summer compared to panels with a brown coating. Engelund et al. (2009) conducted moisture measurements on cladding elements exposed vertically, showing the influence of butt joints and open end grain. They concluded on service life prediction and maintenance periods of coatings as well as the risk of biological decay. Some other studies were carried out with a particular focus on wooden windows (Janotta 1979, Nienhuis and De Meijer 2002, Grüll et al. 2005) but in this case differential climates on the interior and exterior side must be considered as well (Grüll et al. 2006).

The objective of the present work was to observe moisture conditions in coated wood panels in natural weathering according to EN 927-3 at five sites in Europe and to investigate the influence of coating systems and exposure sites.

\section{Material and Methods}

Natural weathering trials were carried out at five sites in Europe with coated wood panels that were produced altogether by one laboratory. Wood moisture content of the panels was recorded weekly by changes in panel mass and on one site additionally by measurements of electric resistance.

\subsection{Sample preparation}

Wood panels were selected and produced according to EN 927-3. Industrially pre-dried Scots pine sapwood (Pinus sylvestris) was used, the wood was straight grained, free from defects and the inclination of the growth rings to the face was $5^{\circ}$ to $45^{\circ}$. The panels were stored at $20^{\circ} \mathrm{C}$ and $65 \%$ relative humidity and they were sanded (grid 150) just before primer application.

Characteristics of the coating systems used are presented in Table 1. Uncoated wood panels were used as a reference at one site. Two topcoats of waterborne acrylic dispersions were used, formulated according to a guidance recipe of the binder supplier, one with semi-transparent brown and the other with opaque white pigmentation. These systems were applied in different target dry film thicknesses, resulting in five water based coating systems. The wood panels were dipped quickly into a water based alkyd primer including dichlofluanide as fungicide and dried before topcoat application. The acrylic dispersions were applied by spraying with an air-assisted airless gun in one (P20) or two layers (P50, P80, W50, W100) depending on the target dry film thickness. The required application rate $\left(\mathrm{g} / \mathrm{m}^{2}\right.$ wet) for each target dry film thickness was calculated by solid-weight content and theoretical build of coating materials. Furthermore the Internal Comparison Product (ICP) as described in EN 927-3, a solvent borne alkyd product, was used. The ICP was applied by brush in 1,2 or 3 layers with a spreading rate of $50 \mathrm{~g} / \mathrm{m}^{2}$ each without additional primer. Liquid water permeability of the coating systems was measured according to EN 927-5 and the results are listed in Table 1.

Three replicates were produced for each coating system and exposure site. The end grain of the panels was treated with a sealer according to EN 927-3, the back sides of the panels were left untreated. A separate set of panels was produced for electric moisture measurements and only these were sealed on the back sides as well. The panels were stored in a controlled environment of $20^{\circ} \mathrm{C}$ and $65 \%$ relative humidity before weathering exposure. 
Table 1: Characterisation of coating systems

\begin{tabular}{|c|c|c|c|c|c|c|c|}
\hline $\begin{array}{l}\text { Coating } \\
\text { system }\end{array}$ & Primer & $\begin{array}{l}\text { Primer } \\
\text { application }\end{array}$ & Top coat & Colour & Thinner & 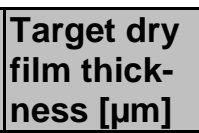 & $\begin{array}{l}\text { WA } \\
\text { EN 927-5 } \\
{\left[\mathrm{g} / \mathrm{m}^{2} 72 \mathrm{~h}\right]}\end{array}$ \\
\hline W50 & \begin{tabular}{|l} 
wb alkyd \\
blue stain protection \\
transparent
\end{tabular} & $\begin{array}{l}\text { dipping on } \\
3 \text { sides }\end{array}$ & $\begin{array}{l}\text { wb acrylic paint } \\
\text { opaque, medium } \\
\text { build }\end{array}$ & white & $\begin{array}{l}\text { water } \\
\text { based }\end{array}$ & $50 \mu \mathrm{m}$ & $356 \mathrm{~g} / \mathrm{m}^{2}$ \\
\hline W100 & $\begin{array}{l}\text { wb alkyd } \\
\text { blue stain protection } \\
\text { transparent }\end{array}$ & $\begin{array}{l}\text { dipping on } \\
3 \text { sides }\end{array}$ & $\begin{array}{l}\text { wb acrylic paint } \\
\text { opaque, high build }\end{array}$ & white & $\begin{array}{l}\text { water } \\
\text { based }\end{array}$ & $100 \mu \mathrm{m}$ & $340 \mathrm{~g} / \mathrm{m}^{2}$ \\
\hline P20 & \begin{tabular}{|l|} 
wb alkyd \\
blue stain protection \\
transparent
\end{tabular} & $\begin{array}{l}\text { dipping on } \\
3 \text { sides }\end{array}$ & $\begin{array}{l}\text { wb acrylic stain } \\
\text { semi transparent } \\
\text { low build }\end{array}$ & $\begin{array}{l}\text { light } \\
\text { brown }\end{array}$ & $\begin{array}{l}\text { water } \\
\text { based }\end{array}$ & $<20 \mu \mathrm{m}$ & $543 \mathrm{~g} / \mathrm{m}^{2}$ \\
\hline P50 & $\begin{array}{l}\text { wb alkyd } \\
\text { blue stain protection } \\
\text { transparent }\end{array}$ & $\begin{array}{l}\text { dipping on } \\
3 \text { sides }\end{array}$ & $\begin{array}{l}\text { wb acrylic stain } \\
\text { semi transparent } \\
\text { medium build }\end{array}$ & $\begin{array}{l}\text { light } \\
\text { brown }\end{array}$ & $\begin{array}{l}\text { water } \\
\text { based }\end{array}$ & $50 \mu \mathrm{m}$ & $481 \mathrm{~g} / \mathrm{m}^{2}$ \\
\hline P80 & $\begin{array}{l}\text { wb alkyd } \\
\text { blue stain protection } \\
\text { transparent }\end{array}$ & $\begin{array}{l}\text { dipping on } \\
3 \text { sides }\end{array}$ & $\begin{array}{l}\text { wb acrylic stain } \\
\text { semi transparent } \\
\text { high build } \\
\end{array}$ & $\begin{array}{l}\text { light } \\
\text { brown }\end{array}$ & $\begin{array}{l}\text { water } \\
\text { based }\end{array}$ & $80 \mu \mathrm{m}$ & $496 \mathrm{~g} / \mathrm{m}^{2}$ \\
\hline $1 \times I C P$ & 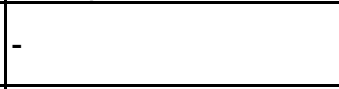 & - & $\begin{array}{l}1 \text { 1xICP semi } \\
\text { transparent alkyd }\end{array}$ & $\begin{array}{c}\text { red- } \\
\text { brown }\end{array}$ & $\begin{array}{l}\text { solvent } \\
\text { based }\end{array}$ & - & - \\
\hline $2 x I C P$ & - & & $\begin{array}{l}\text { 2xICP semi } \\
\text { transparent alkyd }\end{array}$ & $\begin{array}{l}\text { red- } \\
\text { brown }\end{array}$ & $\begin{array}{l}\text { solvent } \\
\text { based }\end{array}$ & - & - \\
\hline $3 \times I C P$ & - & - & $\begin{array}{l}\text { 3xICP semi } \\
\text { transparent alkyd }\end{array}$ & $\begin{array}{l}\text { red- } \\
\text { brown }\end{array}$ & $\begin{array}{l}\text { solvent } \\
\text { based }\end{array}$ & $50 \mu \mathrm{m}$ & - \\
\hline $\mathrm{U}$ & \multicolumn{7}{|l|}{ untreated } \\
\hline
\end{tabular}

\subsection{Natural weathering trials and measurement of wood moisture content}

The panels were exposed to natural weathering starting on 05.11 .2008 for a period of 18 months inclined $45^{\circ}$ facing south at five sites in Europe. Those were the exposure sites of Holzforschung Austria in Vienna (Austria, AT), FCBA in Bordeaux (France, FR), University of Göttingen (Germany, DE), University of Ghent (Belgium, BE) and the BRE in Garston, Watford (UK). The mass of the panels was recorded by the individual labs once week. Wood moisture content was calculated based on an initial equilibrium moisture content of $12 \%$ at $20^{\circ} \mathrm{C}$ and $65 \%$ relative humidity. At the site in Bordeaux the panels were stored inside for a period of approximately two months from November 2009 until January 2010 to carry out assessments. Weather data (temperature, relative humidity and precipitation) was measured or obtained from reliable sources (e.g. Deutscher Wetterdienst) for each site over the period of exposure.

At the site in Vienna measurements of wood moisture by electric resistance and temperature were carried out on a separate set of panels with a Brookhuis MCM data logger in intervals of 30 minutes. Electrodes with insulated shafts were placed in predrilled holes from the backsides of the panels with their tips $3 \mathrm{~mm}$ below the coated surface and the holes were then sealed against moisture ingress. To calculate wood moisture content from electric resistance values the curve 210 for Pinus sylvestris of Brookhuis Micro Electronics BV was used.

\section{Results}

\subsection{Comparison of exposure sites}

Graphs of wood moisture content fluctuations in the coated wood panels at the different sites are shown in Figure 1. Table 2 contains a summary of the same data as mean values and standard deviations separated in time periods. The results showed the highest wood moisture contents at the site in the UK, in particular in winter periods but also during 
summer 2009. Between all other sites differences in wood moisture content were relatively small in the first winter period and larger in summer and the second winter period. By the mean values in Table 2 it can be figured out that in summer 2009 moisture contents at the sites in Austria, Belgium and France were at the same level, somewhat higher at the German site and highest in the UK with all coatings. In Austria a short event of remarkably high wood moisture content was observed in June 2009. The data from France was distorted by the period of storage of the panels in the lab between November 2009 and January 2010. These panels reached similar wood moisture contents as on the other sites in March 2010, but for careful interpretation of this data the values in Table 2 were marked by italic letters.
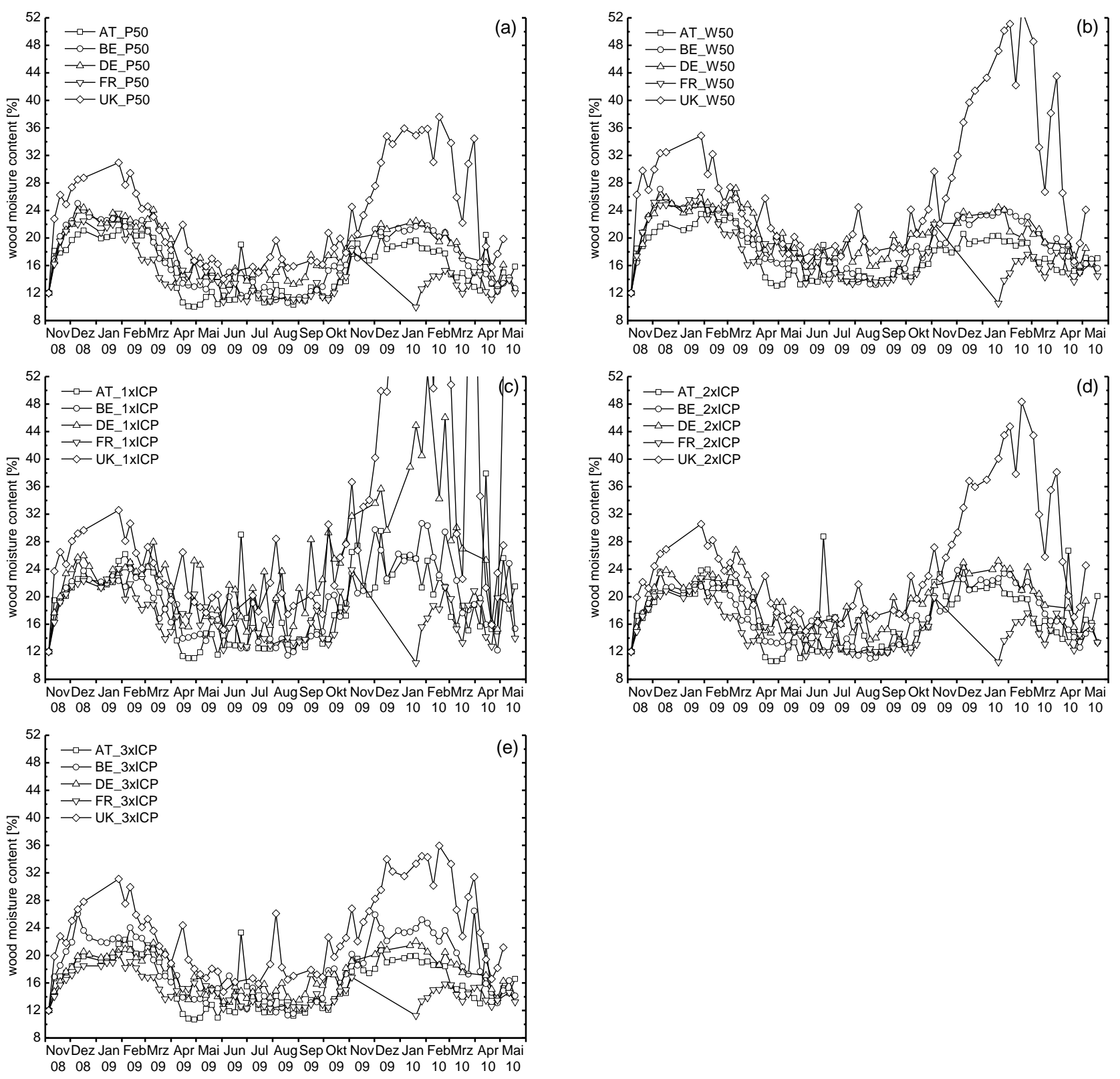

$\begin{array}{lllllllllllllllllllll}08 & 08 & 09 & 09 & 09 & 09 & 09 & 09 & 09 & 09 & 09 & 09 & 09 & 09 & 10 & 10 & 10 & 10 & 10\end{array}$

Figure 1: Wood moisture content of coated wood panels (coating systems P50 (a), W50 (b), 1x ICP (c), 2x ICP (d), 3x ICP(e)) measured by changes in panel mass at five sites in Europe (AT Austria, BE Belgium, DE Germany, FR France, UK) 
Table 2: Summary of wood moisture content measured by changes in panel mass at five sites in Europe separated in time periods (mean \pm standard deviation)

\begin{tabular}{lccccc}
\hline Time period & $\mathbf{1}^{\text {st }}$ winter & $\mathbf{1}^{\text {st }}$ summer & $\mathbf{2}^{\text {nd }}$ winter & $\mathbf{2}^{\text {nd }}$ spring & $\mathbf{1 8 ~ m o n t h s ~}$ \\
\hline Time period & Dec08- & May09- & Dec09- & Mar10- & Nov08- \\
& Feb09 & Sep09 & Feb10 & May10 & May10 \\
\hline AT_U & $28.5 \pm 5.03$ & $15.9 \pm 6.34$ & $27.4 \pm 5.63$ & $23.9 \pm 13.58$ & $22.1 \pm 9.35$ \\
AT_1xICP & $23.2 \pm 1.59$ & $14.9 \pm 3.88$ & $23.7 \pm 2.68$ & $19.5 \pm 6.57$ & $19.1 \pm 5.36$ \\
AT_2xICP & $21.3 \pm 1.53$ & $13.9 \pm 3.75$ & $20.9 \pm 1.36$ & $16.7 \pm 3.52$ & $17.3 \pm 4.26$ \\
AT_3xICP & $20.2 \pm 1.18$ & $13 \pm 2.6$ & $19.2 \pm 0.75$ & $15.2 \pm 2.18$ & $16.1 \pm 3.51$ \\
AT_P50 & $20.7 \pm 0.77$ & $12 \pm 1.92$ & $18.6 \pm 0.85$ & $14.5 \pm 2.13$ & $15.6 \pm 3.75$ \\
AT_W50 & $22.3 \pm 1.08$ & $14.6 \pm 1.37$ & $19.5 \pm 0.62$ & $16.4 \pm 1.13$ & $17.5 \pm 3.16$ \\
\hline BE_1xICP & $22.8 \pm 1.06$ & $14.5 \pm 2.28$ & $26.8 \pm 2.7$ & $18.3 \pm 3.49$ & $19.3 \pm 4.94$ \\
BE_2xICP & $21.4 \pm 0.82$ & $13 \pm 1.43$ & $22.4 \pm 0.86$ & $15.6 \pm 1.89$ & $17.2 \pm 3.89$ \\
BE_3xICP & $22.8 \pm 1.26$ & $13.3 \pm 1.46$ & $23.7 \pm 1.13$ & $17.2 \pm 3.71$ & $18.1 \pm 4.44$ \\
BE_P50 & $22.8 \pm 0.88$ & $12.3 \pm 1.18$ & $21.1 \pm 0.63$ & $14.8 \pm 1.86$ & $16.9 \pm 4.22$ \\
BE_W50 & $24.8 \pm 0.87$ & $15.1 \pm 1.32$ & $23.2 \pm 0.58$ & $17.6 \pm 1.82$ & $19.3 \pm 3.93$ \\
\hline DE_1xICP & $23.9 \pm 1.31$ & $19.5 \pm 3.68$ & $39.5 \pm 7.21$ & $27.9 \pm 12.63$ & $24.7 \pm 8.56$ \\
DE_2xICP & $22.4 \pm 0.92$ & $16.1 \pm 1.74$ & $23.7 \pm 1.3$ & $18.2 \pm 2.47$ & $19.4 \pm 3.66$ \\
DE_3xICP & $20 \pm 0.74$ & $14.7 \pm 1.16$ & $20.7 \pm 1.01$ & $16.7 \pm 1.88$ & $17.3 \pm 2.79$ \\
DE_P50 & $22.8 \pm 0.99$ & $14.8 \pm 1.24$ & $21.3 \pm 0.98$ & $16.6 \pm 2.23$ & $18.2 \pm 3.62$ \\
DE_W50 & $24.6 \pm 0.82$ & $17.7 \pm 1.5$ & $22.7 \pm 1.51$ & $18.8 \pm 1.81$ & $20.6 \pm 3.36$ \\
\hline FR_1xICP & $21.4 \pm 1.65$ & $14.8 \pm 1.76$ & - & $17 \pm 3.05$ & $17.2 \pm 3.33$ \\
FR_2xICP & $20.1 \pm 1.41$ & $13 \pm 1.31$ & - & $14.8 \pm 1.72$ & $15.3 \pm 2.94$ \\
FR_3xICP & $18.4 \pm 0.9$ & $13.3 \pm 1.02$ & - & $14.2 \pm 1.02$ & $14.8 \pm 2.09$ \\
FR_P50 & $21 \pm 1.87$ & $12.1 \pm 1.33$ & - & $13.1 \pm 1.35$ & $14.7 \pm 3.59$ \\
FR_W50 & $24.2 \pm 1.77$ & $15 \pm 1.75$ & - & $15.7 \pm 1.4$ & $17.5 \pm 3.88$ \\
\hline UK_1xICP & $28.6 \pm 2.6$ & $19.4 \pm 2.9$ & $59.1 \pm 11.59$ & $36.1 \pm 19.66$ & $31.2 \pm 16.19$ \\
UK_2xICP & $26.6 \pm 2.17$ & $17.4 \pm 1.47$ & $38.7 \pm 5.67$ & $28 \pm 8.87$ & $24.9 \pm 8.36$ \\
UK_3xICP & $27.3 \pm 2.37$ & $17.6 \pm 2.48$ & $32.4 \pm 2.48$ & $24.1 \pm 5.65$ & $23.4 \pm 5.93$ \\
UK_P50 & $27.9 \pm 2.02$ & $16.2 \pm 1.22$ & $33.8 \pm 3.05$ & $23.6 \pm 7.19$ & $23.1 \pm 6.91$ \\
UK_W50 & $30.4 \pm 3.17$ & $18.8 \pm 1.87$ & $43.7 \pm 6.75$ & $29.7 \pm 10.83$ & $27.5 \pm 9.84$ \\
\hline & & & & &
\end{tabular}

Differences in wood moisture content were more influenced by the exposure site than by the coating system. Nevertheless, between the coating systems the ranking of mean values of wood moisture content was quite uniform at all the sites. Over 18 months exposure the highest mean values of wood moisture content were measured at the coating systems 1x ICP and W50 and the lowest values at the coating system P50 and 3x ICP at all exposure sites. An exception of this was the site in Belgium, where the panels with $2 x$ ICP were slightly dryer than those with $3 x$ ICP. However, one of the three replicates with $3 x$ ICP showed significantly higher values than the other two and therefore, could be regarded as outlier. During the first winter period the ranking of mean values was different to the whole exposure time and between the exposure sites. Consistencies at all sites were found for coating system W50, where the panels were among the two wettest systems, and coating system 3x ICP that was ranked among the two driest systems at four exposure sites. Almost the same ranking as over the whole duration was found in the first summer period but with almost equal mean values for the coating systems $2 x$ ICP and $3 x$ ICP at the sites in Belgium, France and the UK. In the uncoated reference $(U)$ at the site in Austria significantly higher mean values of wood moisture content in winter periods as well as higher fluctuations in all periods were observed compared to all coated panels.

For the coating system $1 \times$ ICP on all sites and for other systems (2x ICP, W50) at the site in the UK higher fluctuations of wood moisture content were measured in the second winter period compared to the first winter period, which was due to degradation of the coatings and cracking of the wood panels. 
Weather data from all sites is shown in Figure 2 and Table 3. At the sites in the UK and in Germany the highest levels of relative humidity over the whole period of weathering with small differences between winter and summer were observed. In the second winter period at the UK site the level of relative humidity was very high with low fluctuations. In the UK and France temperature fluctuations between summer and winter were smaller than on the other sites, temperatures below zero occurred only seldom and the mean value of temperature in summer 2009 was in France one of the highest and in the UK one of the lowest compared to the other sites. In the first period of weathering from November 2008 until February 2009 rainfall was measured frequently at the UK site whereas the other sites showed shorter periods of rain in these months. In Austria high amounts of rain occurred in June 2009, which is in accordance with a short increase in wood moisture content of the panels (Figure 1). Differences in precipitation can also be expressed by the percentage of days with more than $0.1 \mathrm{~mm}$ rainfall. Those were in Germany $52 \%$, in Belgium $48 \%$, in France and the UK 41\% and in Austria only 35\% of the days over the period of 18 months.
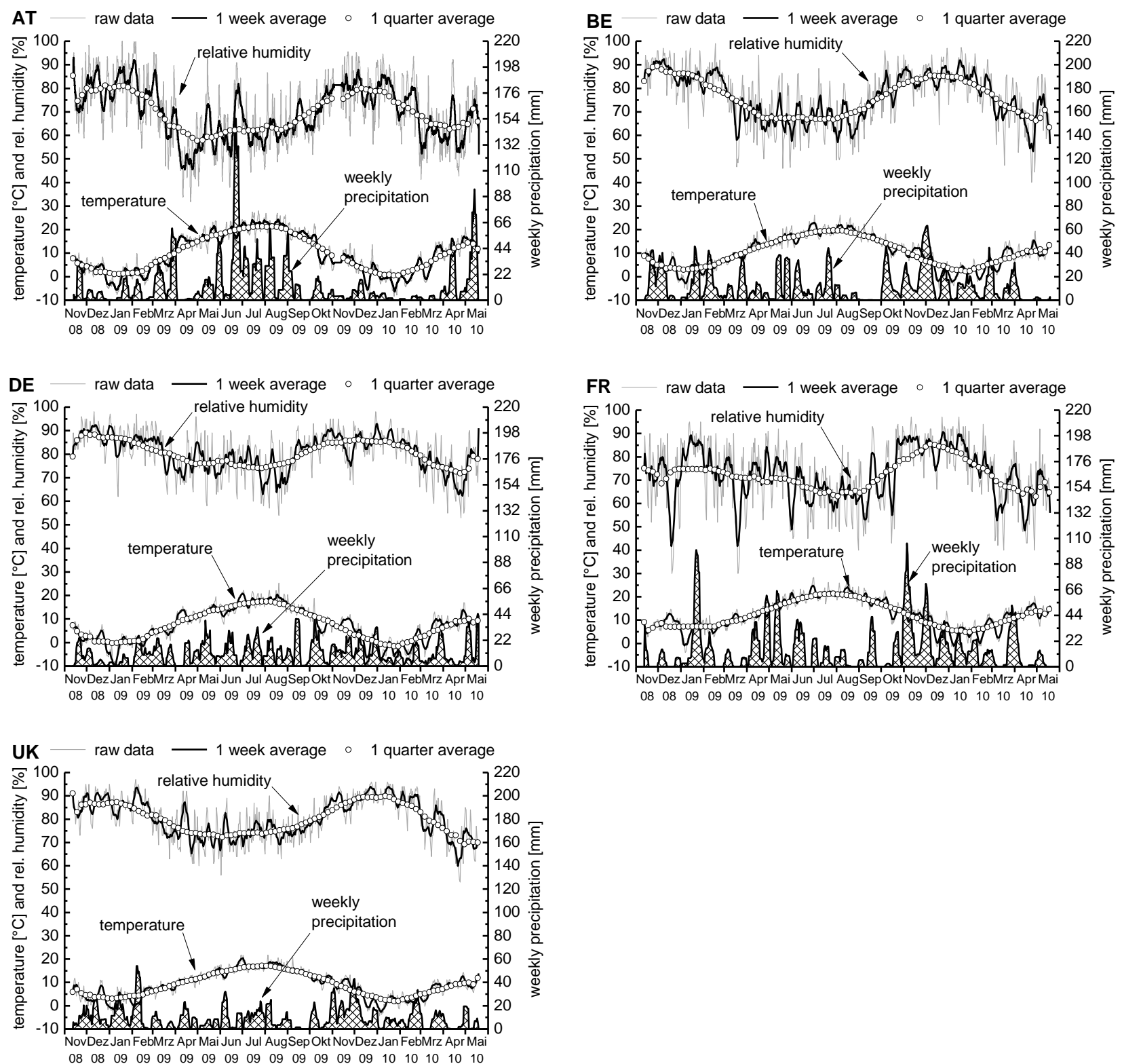

Figure 2: Weather conditions (temperature, relative humidity and precipitation) at five sites in Europe (AT Austria, BE Belgium, DE Germany, FR France, UK) 
Table 3: Summary of weather conditions at five sites in Europe separated in time periods (mean \pm standard deviation)

\begin{tabular}{lccccc}
\hline Time period & $\mathbf{1}^{\text {st }}$ winter & $\mathbf{1}^{\text {st }}$ summer & $\mathbf{2}^{\text {nd }}$ winter & $\mathbf{2}^{\text {nd }}$ spring & $\mathbf{1 8 ~ m o n t h s ~}$ \\
\hline Time period & Dec08- & May09- & Dec09- & Mar10- & Nov08- \\
& Feb09 & Sep09 & Feb10 & May10 & May10 \\
\hline AT_temperature [ $\left.{ }^{\circ} \mathrm{C}\right]$ & $1,2 \pm 3,93$ & $19,9 \pm 4,78$ & $0,7 \pm 4,65$ & $10,4 \pm 6$ & $9,7 \pm 8,95$ \\
AT_rel. humidity [\%] & $80,7 \pm 12,51$ & $62,6 \pm 16,1$ & $77,5 \pm 11,78$ & $62,5 \pm 16,33$ & $69,6 \pm 16,98$ \\
AT_daily precip. [mm] & $0,7 \pm 1,85$ & $3,5 \pm 8,51$ & $0,5 \pm 1,38$ & $2,5 \pm 6,24$ & $1,9 \pm 5,8$ \\
AT_weekly precip. [mm] & $4,9 \pm 5,43$ & $24,4 \pm 28,64$ & $3,6 \pm 4,29$ & $16,3 \pm 23,05$ & $13,1 \pm 20,63$ \\
\hline BE_temperature [ $\left.{ }^{\circ} \mathrm{C}\right]$ & $3,2 \pm 3,41$ & $18,2 \pm 3,07$ & $2,8 \pm 3,72$ & $9,6 \pm 3,81$ & $10 \pm 6,8$ \\
BE_rel. humidity [\%] & $85,7 \pm 6,87$ & $68 \pm 9,35$ & $84,8 \pm 6,5$ & $68,7 \pm 10,29$ & $76,2 \pm 11,82$ \\
BE_daily precip. [mm] & $1,9 \pm 4,28$ & $1,4 \pm 4,33$ & $2,3 \pm 3,81$ & $0,7 \pm 1,82$ & $1,7 \pm 3,71$ \\
BE_weekly precip. [mm] & $13,4 \pm 14,03$ & $9,6 \pm 12,75$ & $15,6 \pm 15,37$ & $6 \pm 8,56$ & $12,2 \pm 13,71$ \\
\hline DE_temperature [ $\left.{ }^{\circ} \mathrm{C}\right]$ & $0 \pm 4,49$ & $15,8 \pm 3,31$ & $-1,1 \pm 4,71$ & $7,3 \pm 4,45$ & $7,2 \pm 7,49$ \\
DE_rel. humidity [\%] & $86,8 \pm 6,28$ & $75,8 \pm 8,8$ & $85,5 \pm 5,4$ & $73,5 \pm 9,02$ & $80,4 \pm 9,24$ \\
DE_daily precip. [mm] & $1 \pm 1,76$ & $1,9 \pm 3,77$ & $1,5 \pm 2,61$ & $1,6 \pm 3,38$ & $1,6 \pm 3,19$ \\
DE_weekly precip. [mm] & $6,7 \pm 6,38$ & $13,5 \pm 10,02$ & $10,3 \pm 8,09$ & $11,4 \pm 11,99$ & $11,2 \pm 9,43$ \\
\hline FR_temperature [ $\left.{ }^{\circ} \mathrm{C}\right]$ & $7,2 \pm 3,74$ & $19,8 \pm 3,07$ & $5,5 \pm 4,41$ & $11,6 \pm 4,17$ & $12,1 \pm 6,45$ \\
FR_rel. humidity [\%] & $74,8 \pm 14,73$ & $66,3 \pm 11,55$ & $81,8 \pm 8,38$ & $64,5 \pm 12,08$ & $72,1 \pm 13,8$ \\
FR_daily precip. [mm] & $2,1 \pm 5,03$ & $1,8 \pm 4,21$ & $2,3 \pm 3,9$ & $1,3 \pm 2,95$ & $2,1 \pm 4,53$ \\
FR_weekly precip. [mm] & $14,4 \pm 23,72$ & $12,8 \pm 15,38$ & $16,3 \pm 13,68$ & $9,5 \pm 14,56$ & $14,4 \pm 18,71$ \\
\hline UK_temperature [ [ $\mathrm{C}$ ] & $3,3 \pm 3,42$ & $15,7 \pm 2,59$ & $2,5 \pm 3,12$ & $8,1 \pm 3,16$ & $8,8 \pm 5,79$ \\
UK_rel. humidity [\%] & $87 \pm 4,88$ & $73,8 \pm 6,37$ & $90 \pm 3,93$ & $73,4 \pm 8,35$ & $80,3 \pm 9,18$ \\
UK_daily precip. [mm] & $1,9 \pm 3,8$ & $1,1 \pm 2,9$ & $1,5 \pm 2,3$ & $0,8 \pm 2,2$ & $1,4 \pm 2,92$ \\
UK_weekly precip. [mm] & $13,8 \pm 12,78$ & $7,7 \pm 7,61$ & $10,7 \pm 8,73$ & $5,7 \pm 6,44$ & $9,7 \pm 9,47$ \\
\hline & & & & & \\
\hline
\end{tabular}

\subsection{Comparison of coating systems}

A comparison of the coating systems used and the uncoated reference by electric measurements of wood moisture content at the exposure site in Vienna, Austria is shown in Figure 3. This data reflects the moisture conditions in the uppermost layer, where the pins for electric resistance measurements were placed in the exposed panels with sealed backsides. The uncoated reference showed a significantly higher level of wood moisture content over the whole period of weathering than most of the coating systems. In June 2009 all panels showed a short increase of wood moisture content that can be related to an event of heavy rainfall in Vienna as described above. It is remarkable that the rises in moisture content at this event showed consistencies with coating film thickness, liquid water permeability and condition of the coating systems.

Only the panels with $1 \mathrm{x}$ ICP followed the same course of moisture content as the uncoated reference from April 2009 after an initial phase with lower moisture content. This was in accordance with relatively fast coating degradation and occurrence of cracks in the wood panels. There was a clear ranking by increasing moisture protection for the coating systems $1 \mathrm{x} I \mathrm{CP}, 2 \mathrm{x}$ ICP and 3x ICP, which was even more pronounced in winter periods.

The panels with the semi transparent stain systems P20, P50 and P80 all behaved very similar over the first winter and spring period and moisture level was higher than in the panels with 2x ICP and 3x ICP. Starting with the rain event in June 2009 wood moisture contents became different in a ranking by increasing film thickness of the coatings P20, P50 and P80. During summer 2009 moisture fluctuations increased with the coating system P20 and in the same period signs of coating degradation and cracks were found on the panels. However, moisture level still remained lower than in the uncoated reference. During the first summer period wood moisture content of the systems P50 and P80 was equal to the one of the systems $2 x$ ICP and 3x ICP. Starting in February 2010 coating system P50 showed a similar behaviour as system P20 and in March 2010 the values of system P80 also started fluctuating higher. 
The opaque white coating systems W50 and W100 revealed a similar behaviour, characterised by high levels of moisture content during the first winter but also in the first summer period compared to all other coating systems. Short term fluctuations of moisture content remained low over the whole duration of weathering and consistently the panels showed no signs of severe coating degradation.

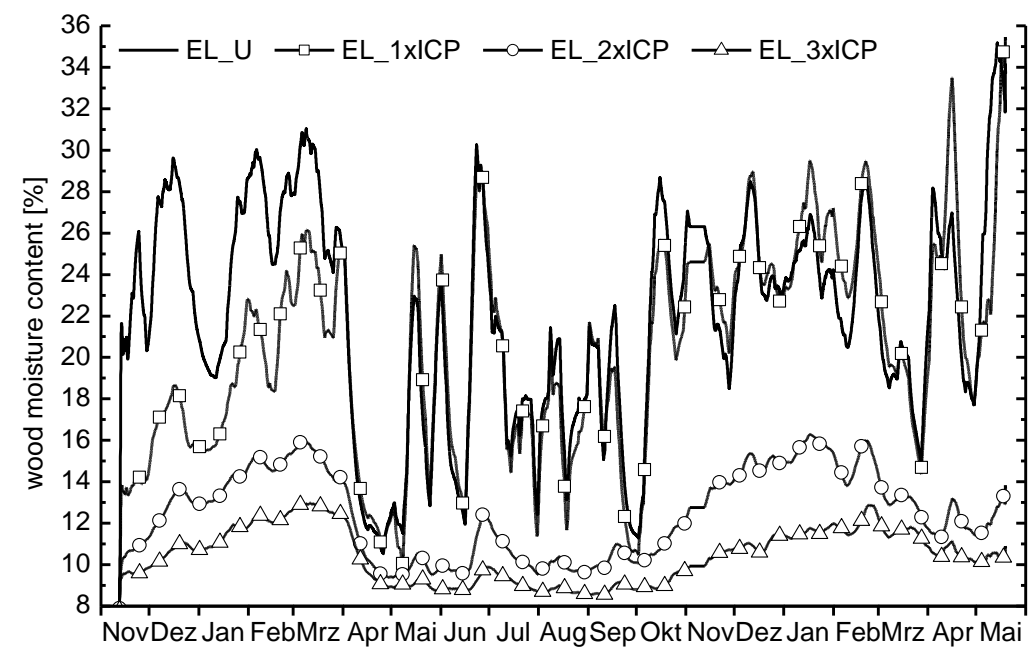

$\begin{array}{lllllllllllllllllll}08 & 08 & 09 & 09 & 09 & 09 & 09 & 09 & 09 & 09 & 09 & 09 & 09 & 09 & 10 & 10 & 10 & 10 & 10\end{array}$
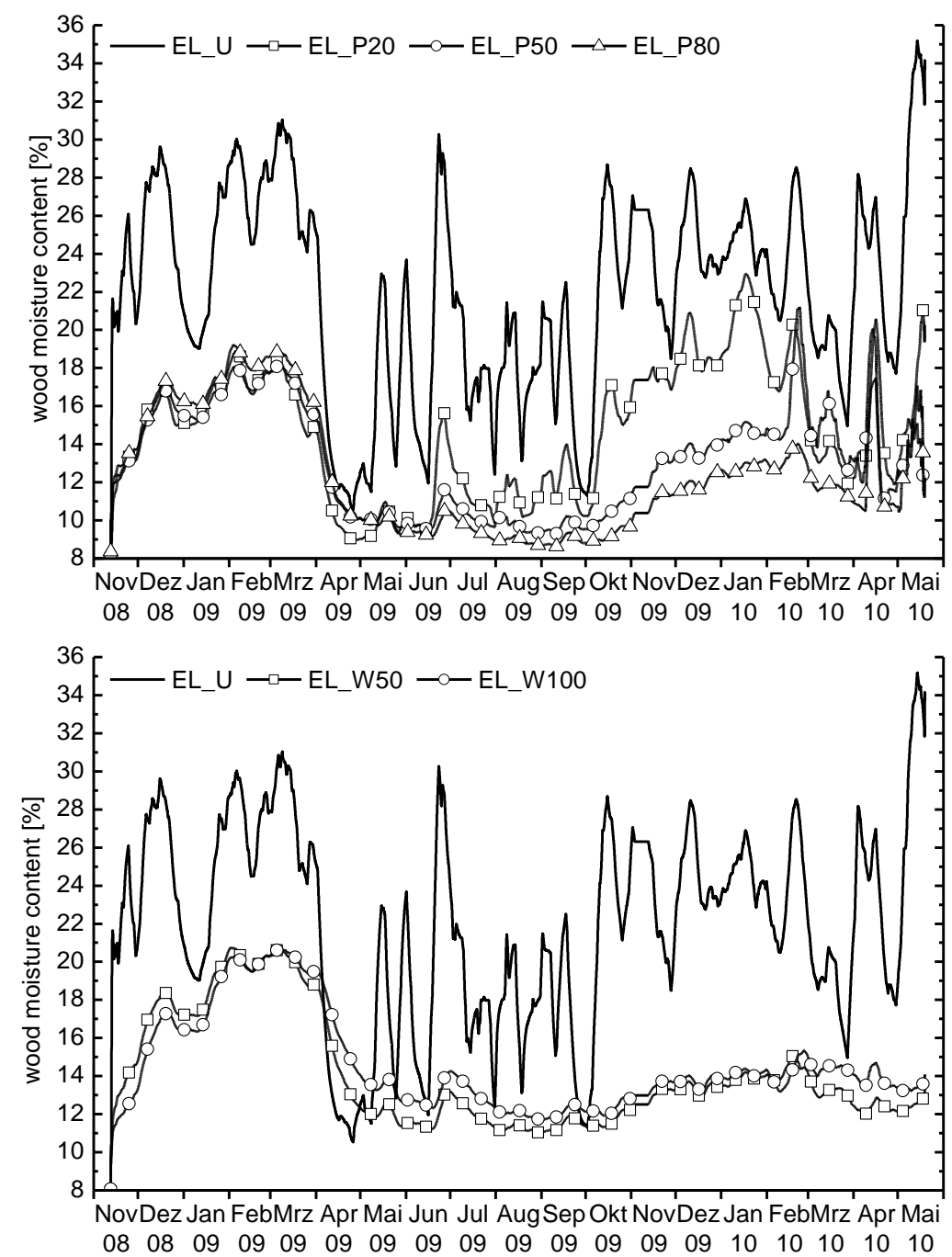

Figure 3: Wood moisture content (smoothed by weekly average) of coated wood panels (coating systems 1x ICP , 2x ICP, 3x ICP, P20, P50, P80, W50, W100, U uncoated reference) measured by electric resistance (EL) at the site in Vienna 
A summary of the same data separated in time periods is included in Table 4 and Figure 4. By comparing the mean values in the first and second winter period the marked loss of moisture protection of the systems 1X ICP and P20 can be figured out and a somewhat less pronounced increase in moisture level was found for system 2x ICP. With all other coating systems equal or even lower moisture conditions were observed in the second winter. In particular for the coating systems P80, W50 and W100 moisture level was significantly lower in the second winter period. Weather data for the site in Austria (Figure 2) indicated a lower amount of rainfall in the second winter than in the first one.

Table 4: Summary of wood moisture content measured by electric resistance (EL) in Vienna separated in time periods (mean \pm standard deviation)

\begin{tabular}{lccccc}
\hline Time Period & $\mathbf{1}^{\text {st }}$ winter & $\mathbf{1}^{\text {st }}$ summer & $\mathbf{2}^{\text {nd }}$ winter & $\mathbf{2}^{\text {nd }}$ spring & $\mathbf{1 8 ~ m o n t h s ~}$ \\
\hline Time period & Dec08- & May09- & Dec09- & Mar10- & Nov08- \\
& Feb09 & Sep09 & Feb10 & May10 & May10 \\
\hline EL_UNC & $25.4 \pm 4.27$ & $18 \pm 6.48$ & $24.6 \pm 2.83$ & $22.9 \pm 6.44$ & $21.9 \pm 6.39$ \\
EL_1xICP & $18.5 \pm 3.04$ & $17.8 \pm 6.53$ & $25.8 \pm 3.14$ & $22.5 \pm 6.31$ & $20.3 \pm 6.09$ \\
EL_2xICP & $13.8 \pm 1.1$ & $10.2 \pm 0.87$ & $15.2 \pm 0.86$ & $12.4 \pm 1.01$ & $12.5 \pm 2.16$ \\
EL_3xICP & $11.4 \pm 0.81$ & $9 \pm 0.48$ & $11.5 \pm 0.67$ & $10.9 \pm 0.81$ & $10.4 \pm 1.37$ \\
EL_P20 & $16.6 \pm 1.4$ & $11.2 \pm 1.95$ & $19.3 \pm 2.02$ & $14.4 \pm 3.17$ & $14.6 \pm 3.68$ \\
EL_P50 & $16.4 \pm 1.12$ & $10 \pm 0.73$ & $14.9 \pm 2.45$ & $14 \pm 4.24$ & $13.1 \pm 3.31$ \\
EL_P80 & $17.1 \pm 1.28$ & $9.4 \pm 0.75$ & $12.6 \pm 0.84$ & $12.4 \pm 3.74$ & $12.4 \pm 3.39$ \\
EL_W100 & $17.9 \pm 1.87$ & $12.7 \pm 0.84$ & $14 \pm 0.63$ & $14 \pm 0.81$ & $14.6 \pm 2.56$ \\
EL_W50 & $18.6 \pm 1.49$ & $11.7 \pm 0.71$ & $13.8 \pm 0.69$ & $12.7 \pm 0.7$ & $14.1 \pm 2.92$
\end{tabular}

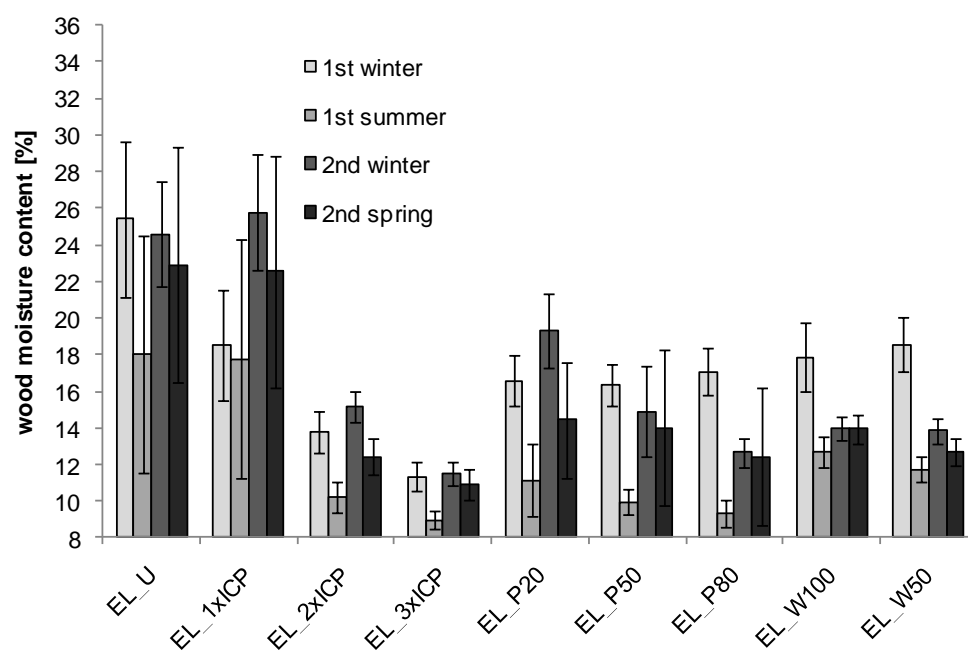

Figure 4: Wood moisture content of coated wood panels measured by electric resistance (EL) at the site in Vienna separated in time periods (mean \pm standard deviation)

\section{Discussion}

In the observed period of 18 months natural weathering changes in wood moisture content in short periods and between summer and winter were captured. A few coating systems have already shown signs of degradation that led to decreasing moisture protection and hence, increasing moisture fluctuations in the panels. The results confirm that the occurrence of cracks indicates a limit state of the coated element that requires maintenance (Grüll et al. 2010). The experiments will be continued to observe ongoing degradation of the coatings and its impact on wood moisture content. The results enable a 
good comparison of exposure sites spread over Europe. Data from other exposure sites, in particular in northern and southern Europe is available to be assessed in the same way.

The two methods employed to measure wood moisture content in the present study by recording panel mass and measuring electric resistance must be interpreted differently. Panel mass data gives evidence on the average wood moisture content of the whole panel whereas the electric measurements indicate moisture conditions in the uppermost region of the boards, closely to the weathered surface. Furthermore, it must be considered that the panels for mass recording were not sealed at the backsides whereas those for electric measurements were sealed. Hence, the panels for mass recording could take up and release moisture over the backsides as well. Both explains smaller differences between the coating systems from panel mass data than from electric measurements but still a clear influence of the coatings and a similar ranking at all sites was achieved also with panel mass data. In practice these two methods can reflect different construction details or exposure situations, e.g. boards in a wood cladding coated on the front side, with or without ventilation of the backsides. An influence of the coating system on claddings with ventilated backsides was also reported by Fitl et al. (2007).

\subsection{Comparison of exposure sites}

The exposure site clearly affected wood moisture content in the panels. Except the site in the UK, which was the most humid one, differences in wood moisture content between the exposure sites were relatively small but in accordance with varying weather data. The influence of weather parameters is complex and not all relevant factors were recorded in weather data, like for instance irradiation from sunlight. The influence of precipitation on wood moisture content of the panels is difficult to capture with a simple parameter. The duration of continuous rain is more relevant than the amount of rainfall (Rapp et al. 2000, De Windt et al. 2009). At the individual sites fluctuations in temperature and relative humidity corresponded with changes in wood moisture content, which is in accordance with the findings of De Windt et al. (2009) and Engelund et al. (2009).

Wood moisture contents at the UK site exceeded the other sites because of a combined appearance of some factors leading to humid conditions. Those were high levels of relative humidity over the whole period of weathering, low fluctuations in temperature between winter and summer, with most values above zero in winter and low temperatures in summer as well as frequent rainfall in the first period of weathering. Higher wood moisture contents in summer 2009 at the site in Germany were related to lower temperatures and a higher level of relative humidity compared to the other sites. It was surprising that the sites in Austria, Belgium and France obtained very similar results not only in magnitude of moisture fluctuations but even in values of wood moisture content for a number of coating systems. This can be explained by corresponding weather data, in particular days with rainfall and levels of relative humidity. Differences in temperature between these sites were less pronounced in wood moisture data.

The similarities in ranking of the coating systems by mean values of wood moisture content indicate an influence of the coating systems despite their effect was smaller than the differences between the exposure sites. These rankings were also in accordance with the more pronounced differences between the coating systems observed by electric measurements in Vienna. The minor differences between the coating systems were caused by the unsealed backsides of the panels for mass recording, that allowed moisture compensation between the panels and the environment as described above. Larger differences can be expected when panels with sealed backsides are used.

The data gives evidence on moisture conditions in coated wood during natural weathering at five sites in Europe and may contribute to modelling of decay risk and service life 
prediction of coated wood constructions on a European level (Brischke 2007, Viitanen et al. 2010).

\subsection{Comparison of coating systems}

The results confirm the findings of (Derbyshire and Miller 1996) and can be easily compared to this study because of very similar methodology. In contrast, lower levels of wood moisture content were measured in summer periods and larger long term fluctuations between summer and winter were observed. This, however, is due to variability in weather conditions and exposure site.

Wood moisture content was influenced by the type of binder, the film thickness and the colour of the coating systems. The first two are major factors to determine coating permeability (Janotta 1973, Ekstedt 2002). In particular the differences in short term moisture increase in June 2009 can be attributed to liquid water permeability and condition of the coating systems. With the solvent borne alkyd stain (ICP) in higher film thicknesses lower moisture levels were maintained in winter periods compared to the water based acrylic stains. The relevance of film thickness was evident right from the start of exposure with the solvent based alkyd stains (ICP). In contrast the water based acrylic stains behaved similar over the first winter but their degradation and successive loss of moisture protection occurred in the order of their film thickness starting from the lowest. It can be concluded that high film thicknesses contribute to better moisture protection, higher coating durability and longer maintenance intervals. However, they can have negative consequences of low coating permeability when moisture enters the wood via constructive gaps or coating defects and it can only be released very slowly (De Windt et al. 2009, Viitanen et al. 2010).

The light colour of the white opaque paints led to higher levels of wood moisture content in the panels compared to those with brown and red stains, in particular in summer but also in the first winter period. This confirms the results of Fitl et al. (2007) and Janotta (1979) and can be explained by less energy absorption from sunlight of these panels. It can be concluded that the white opaque coatings tested are durable and reduce moisture fluctuations in wood but lead to generally higher moisture levels. With both white coating systems wood moisture content measured electrically on panels with sealed backsides remained below critical limits over the whole duration of exposure.

Wood moisture contents of less than $20 \%$ were maintained with most of the coating systems for longer periods before surface degradation and a corresponding loss of moisture protection occurred. The degree of moisture protection and coating durability is influenced by coating film thickness as well as the type of coating as described above. The comparison to uncoated wood underpins the effect of wood coatings to reduce decay risk of wood but this must be related to proper detailing of wood constructions to avoid irregular moisture ingress and allow rapid drying. The results also give evidence on differences in coating durability and the need of maintenance to restore their protective function. In this aspect, however, the accelerated weathering conditions in $45^{\circ}$ south exposure relative to vertically installed elements (e.g. claddings) and decelerated conditions relative to more flat or nearly horizontal surfaces (e.g. decking) must be considered.

\section{Conclusions}

In natural weathering trials with coated panels of Scots pine sapwood at five sites in Europe over 18 months changes in wood moisture content in short periods and between summer and winter were captured. Fluctuations in temperature and relative humidity corresponded with changes in wood moisture content. The exposure site clearly affected wood moisture content in the panels. High wood moisture contents at the UK site were 
related to a combined appearance of some factors leading to humid conditions, like high levels of relative humidity, low fluctuations in temperature and frequent rainfall in the first period of weathering. Regarding the influence of precipitation the duration of continuous rain is more relevant than the amount of rainfall.

Wood moisture content was influenced by the type of binder, the film thickness and the colour of the coating systems. Coating degradation and successive loss of moisture protection occurred in the order of increasing film thickness at the stains used. High film thicknesses contributed to better moisture protection, higher coating durability and longer maintenance intervals. However, they can have negative consequences of low coating permeability when moisture enters the wood and it can only be released very slowly. Solvent borne alkyd stains maintained lower levels of wood moisture content than water based acrylic stains. The white opaque coatings tested are durable and reduce moisture fluctuations in wood but lead to generally higher moisture levels compared to panels with brown and red stains due to less energy absorption from sunlight.

The data gives evidence on moisture conditions in coated wood during natural weathering at five sites in Europe and may contribute to modelling of decay risk and service life estimation of coated wood constructions on a European level.

\section{Acknowledgements}

The authors gratefully acknowledge the financial support of WoodWisdom-Net (www.woodwisdom.net), the Austrian Research Promotion Agency (FFG) and the wood industry partnership Building with Wood for funding the research work within project "WoodExter". This work forms part of that project. The "WoodExter" research partners are thanked for their cooperation and collaboration in this project.

\section{References}

Brischke C (2007): Untersuchung abbaubestimmender Faktoren zur Vorhersage der Gebrauchsdauer feuchtebeanspruchter Holzbauteile. Dissertation. Hamburg. Universität.

De Meijer M, Militz H (2001): Moisture transport in coated wood. Part 2: Influence of coating type, film thickness, wood species, temperature and moisture gradient on kinetics of sorption and dimensional change. Holz Roh Werkstoff, 58, -467 - 475.

De Windt I, Van den Bulcke J, van Acker J (2009): Continuous moisture measurement (CMM) to detect failure of moisture resistance. International Research Group on Wood Preservation, IRG/WP 09-20422.

Derbyshire H, Miller E R (1996): Moisture conditions in coated exterior wood. Part 3: Moisture content during natural weathering. J. Inst. Wood Sci., 4, 14, -169 - 174.

Ekstedt J (2002): Studies on the barrier properties of wood coatings. Royal Institute of Technology, Stockholm.

Engelund E T, Lindegaard B, Morsing N (2009): Service Life Prediction of Wood Claddings by in-situ Measurement of Wood Moisture Content: Status after 5 years of Outdoor Exposure. International Research Group on Wood Preservation, IRG/WP 09-20401.

Fitl R, Gamerith H, Höfler K, Grüll G, Schober K P (2007): Bauphysikalische Ausführung von Holzfassaden für den Bereich des Wärmeschutzes und des Feuchtehaushaltes. Arbeitsheft 9/07 proHolz Austria, Vienna. 
Grüll G, Anderl T, Schweiger I (2005): Wood Moisture Content of Coated Wood/Aluminium Windows During Three Years of Natural Weathering. Holz Roh Werkstoff, 63, 334341.

Grüll G, Fitl R, Teischinger A (2006): Computer Modelling of Steady-State Moisture Diffusion Through Wood/Aluminium Windows with Different Coatings. Surface Coatings International Part B: Coatings Transactions, 89, B2, 99-192.

Grüll G, Truskaller M, Podgorski L, Bollmus S, Tscherne F (2010): Maintenance procedures and definition of limit states for exterior wood coatings. Eur. J. Wood Prod., 68 , in press.

Hora G, Böttcher P (1995): Feuchtephysikalische Eigenschaften von fachwerkspezifischen Dispersionen. farbe + lack, 3, 101, -296 - 300.

Janotta O (1973): Die Wasserdampfdurchlässigkeit von Anstrichmitteln Teil 2. Holzforschung Holzverwertung, 2, 25, -35 - 38.

Janotta O (1979): Der Einfluß des Farbtones und der Wasserdampfdurchlässigkeit von Anstrichmitteln auf die Feuchtigkeitsverteilung im Holz. Auswirkungen auf die Kondenswasserbildung an Holzverbundfenstern. Holzforschung Holzverwertung, 3, $31,-45-59$.

Nienhuis J, De Meijer M (2002): Real Time Moisture Content Measurement in Full Scale Window Frames. Proceedings $3^{\text {rd }}$ International Wood Coatings Congress, The Hague 2002.

Rapp A O, Peek R D, Sailer M (2000): Modelling of Moisture Induced Risk of Decay for Treated and Untreated Wood Above Ground. Holzforschung, 54, 2, 111-118.

Svane $P$ (2004): Painted wood stands the test of time. European Coatings Journal, 5 , 2004, $-38-42$.

Viitanen $\mathrm{H}$, Toratti T, Makkonen L, Peuhkuri R, Ojanen T, Ruokolainen L, Räisänen J (2010): Towards modelling of decay risk of wooden materials. Eur. J. Wood Prod., 68, 3, 303-313.

Wassipaul F, Janotta O (1972): Die Wasserdampfdurchlässigkeit von Anstrichmitteln Teil 1. Holzforschung Holzverwertung, 4, 24, -74 - 79.

\section{Speaker and contact:}

Dr. Gerhard Grüll Holzforschung Austria Franz Grill Strasse 7

A-1030 Wien

Austria

Tel.: +431798262361

Fax: +431798262350

e-mail: g.gruell@holzforschung.at 